\title{
Correction to: Weak-Type Estimates for the Metaplectic Representation Restricted to the Shearing and Dilation Subgroup of $S L(2, \mathbb{R})$
}

\author{
Alessandra Cauli
}

\section{Correction to:}

Chapter 3 in: P. Boggiatto et al. (eds.), Landscapes of Time-Frequency Analysis, Applied and Numerical Harmonic Analysis, https://doi.org/10.1007/978-3-030-05210-2_3

The original version of the book was inadvertently published with incorrect author name in chapter 3. The author's name "Allesandra Cauli" name has been replaced with a revised name as "Alessandra Cauli". The chapter and book have been updated with the changes. 